http://jmscr.igmpublication.org/home/ ISSN (e)-2347-176x ISSN (p) 2455-0450

crossref DOI: https://dx.doi.org/10.18535/jmscr/v8i4.80

\author{
Journal Of Medical Science And Clinical Research \\ IGM Publication \\ An official Publication of IGM Publication
}

\title{
Camphor Addiction: A Prospective Study of Camphorated Oil Use \& Its Outcome over the Period of 10 Years in Tertiary Care Centre
}

\author{
Author \\ Mishra V N \\ Professor, Department of Neurology, Institute of Medical Sciences, Banaras Hindu University, \\ Varanasi, Uttar Pradesh, India
}

\begin{abstract}
Camphor addiction is common problem in India and it causes neurological symptoms of addiction and withdrawal, which affects the person's activity of daily living. In present paper we have analyzed, 1233 patients addicted to camphorated oil over more than 5 years duration. Headache, Insomnia, vertigo, depression, Visual blurring (118 patients) were the common clinical presentation in patients with camphorated oil addiction and 12 of the patients had Intracerebral bleed at time of presentation. Neuroimaging showed brain atrophy in 22 patients. $42 \%$ of these patients had re-addiction in follow up, due to firm belief about its medicinal use and withdrawal symptoms. It was concluded that, high end advertisements, lack of restriction of availability, misinformation printed on leaflets, persistent symptoms were the primary cause of chronic use leading to addiction.

Keywords: Camphor, Addiction, Headache, Visual loss.
\end{abstract}

\section{Introduction}

Camphor (Cinnamomum camphora) is an organic compound commonly used in creams, ointments, and lotions. Camphor oil is the oil extracted from the wood of camphor trees and processed by steam distillation. Camphor have been used, globally since ages for recreational, medicinal and flavor purposes. In India, however, camphor tablets are used in Hindu religious ceremonies for aarti or lamps lighting to deities. It is also been used in many forms medicinal purposes like analgesics, abortificents, aphrodisiacs and as an antifungal agent ${ }^{(1)}$. Although camphor is not recognized as a potentially toxic compound in general $^{(2)}$ studies have identified its neurotoxic effects following ingestion, inhalation and dermal exposure $^{(3)}$. Due to its toxic nature Camphor levels in various products have been described and products with permissible limits have been only permitted to be marketed globally. Around 3-5 $\mathrm{mL}$ of $20 \%$ camphor oil or $>30 \mathrm{mg} / \mathrm{Kg}$ is a potentially lethal dose in literature causing seizures and death $^{(4)(5)}$.

In India, camphor is openly sold in general market and no permissible limits for the Camphor use have been described. Even for medicinal purposes, neither any permissible limits have been described nor does any regulatory body care for the same. Due to such laxity in rules India especially North India is mammoth market for camphorated products used in various forms for medicinal use. It is being marketed as Oil, as analgesic creams, as aphrodisiacs, as abortifients, and all such products are openly sold as an over 
the counter drugs ${ }^{(6)}$. Due to such open market and easy availability, camphor is frequently used as an addictive product, knowingly or unknowingly.

Camphor toxicity has been described well in literatures ${ }^{(7)}$, but no other study has been done on camphor product users who have been addicted to same. This is the first prospective study of camphorated oil users, who have been using it since last 5 years, and its effects have been discussed in detail. In this paper, we have prospective registered cases of camphorated oil users, who have been using camphorated oil in any form for more than 5 years, with $>3$ times a week. All such patients were analyzed with detailed history and clinical examination and neuroimaging.

\section{Materials \& Methods}

All the patients presenting to Neurology Outpatient Department in SS Hospital, Varanasi, India from June 2011 to January 2020 where screened for use of camphorated oil in any form for more than three days in a week for more than 5 years were registered in the present study. Detailed clinical history, demographic data was taken with special reference to the factors leading to addiction, associated addiction, duration, characteristics of Headache, Vertigo, lightheadedness, neck pain. All patients were examined with special focus on fundus examination, focal neurological deficits. Hamilton depression Scale, mini mental state examination was done when necessary. All the patients were screened by Computed Tomography head and Magnetic Resonance Imaging was performed in 129 patients, including those who had history of visual blurring. Visual Evoked potential was studied in those patients who had features of visual loss.

\section{Result}

From June 2011 to January 2020, total 18,039 headache patients were screened and questioned about topical use of camphorated oil. 4783 (26.51\%) patients were found to having use of camphorated oil (>3 times in week). We further screened 1233 patients who were chronic users of camphorated oil and were addicted to the use of camphorated oil. Of 1233 patients, only 19 (1.5\%) patients were males and 1214 (98.5\%) were females. Age ranged from 23 years to 78 years. Detailed clinical findings are shown in Table 1 and associated clinical features are listed in Table 2.

Table 1: Camphorated Oil addicted patients: Clinical details

\begin{tabular}{|l|l|}
\hline Total no. of headache patients screened & 18,039 \\
\hline $\begin{array}{l}\text { Camphorated Oil users } \\
\text { (Using Camphorated oil }>\mathbf{3} \text { days in week) }\end{array}$ & 4783 \\
\hline $\begin{array}{l}\text { Camphorated Oil addicted patients } \\
\text { (Using Camphorated oil }>\mathbf{3} \text { days in week, for >5 } \\
\text { years) }\end{array}$ & 1233 \\
\hline $\begin{array}{l}\text { How did they get information about camphorated } \\
\text { Oil (n=1233) }\end{array}$ & $\begin{array}{l}\text { Personal communication (42\%), Quack's practitioners } \\
\text { prescription (14\%), Physician's prescription (10\%), } \\
\text { Drug store man prescription (17\%), Bought after } \\
\text { reading indications (22\%) }\end{array}$ \\
\hline Cause for use of Camphorated oil (n=1233) & $\begin{array}{l}\text { Headache, Vertigo, Lightheadedness, Insomnia, } \\
\text { Mental Retardation, Forgetfulness, Decrease Libido, } \\
\text { Impotency, Constipation }\end{array}$ \\
\hline Withdrawal features (n=1233) & Insomnia, Agitation, Depression, Suicidal thoughts \\
\hline Associated illness $(\mathbf{n}=\mathbf{1 2 3 3})$ & Visual impairment, Cerebral Atrophy \\
\hline
\end{tabular}


Table 2: Camphorated Oil addicted patients: Associated features

\begin{tabular}{|l|c|}
\hline Parameters & Number of patients \\
\hline Patients with H/O Visual Blurring & 118 \\
\hline Focal Neurological Deficit & 12 \\
\hline Brain Atrophy & 22 \\
\hline Optic Neuritis & None \\
\hline MMSE & MCI : 19 \\
\hline HMDS & Depression: 41 \\
\hline Re-addiction & 505 \\
\hline
\end{tabular}

MR imaging of brain showed cerebral atrophy in 22 patients of 118 patients, who complained of Visual blurring, neither had abnormal fundus findings, none of these patients had evidence of optic nerve hyper intensity on imaging. Of these 22 patients, 14 were analyzed for serum Vitamin B12 level and were found to be on lower limit. Total 19 patients were found to have, mild cognitive impairment on MMSE and of these 19 MCI patients 9 had brain atrophy on CT scan head and 8 lower level of Vitamin B12 level in blood.

Table 3: Clinical details of patients with Lower Vitamin B12 level

\begin{tabular}{|l|c|c|c|c|c|}
\hline $\begin{array}{l}\text { Case } \\
\text { No. }\end{array}$ & $\begin{array}{c}\text { Age (Yrs)/ } \\
\text { Sex }\end{array}$ & Religion & $\begin{array}{c}\text { H/O Visual } \\
\text { Blurring }\end{array}$ & $\begin{array}{c}\text { Mild Cognitive } \\
\text { Impairment }\end{array}$ & Neuroimaging \\
\hline 1. & $52 / \mathrm{F}$ & Hindu & Present & Present & Brain Atrophy \\
\hline 2. & $48 / \mathrm{F}$ & Hindu & Present & Present & Brain Atrophy \\
\hline 3. & $33 / \mathrm{F}$ & Muslim & Present & Present & Brain Atrophy \\
\hline 4. & $41 / \mathrm{F}$ & Hindu & Present & Present & Brain Atrophy \\
\hline 5. & $48 / \mathrm{F}$ & Hindu & Present & Present & Brain Atrophy \\
\hline 6. & $66 / \mathrm{F}$ & Hindu & Present & Present & Brain Atrophy \\
\hline 7. & $29 / \mathrm{F}$ & Hindu & Present & Present & Brain Atrophy \\
\hline 8. & $31 / \mathrm{F}$ & Hindu & Present & Present & Brain Atrophy \\
\hline 9. & $24 / \mathrm{F}$ & Hindu & Present & Absent & Brain Atrophy \\
\hline 10. & $61 / \mathrm{F}$ & Hindu & Present & Absent & Brain Atrophy \\
\hline 11. & $47 / \mathrm{F}$ & Hindu & Present & Absent & Brain Atrophy \\
\hline 12. & $28 / \mathrm{F}$ & Muslim & Present & Absent & Brain Atrophy \\
\hline 13. & $30 / \mathrm{F}$ & Hindu & Present & Absent & Brain Atrophy \\
\hline 14. & $55 / \mathrm{F}$ & Hindu & Present & Absent & Brain Atrophy \\
\hline
\end{tabular}

\section{Discussion}

Camphor addiction is an underreported disorder in India and camphor is in rampant use in North India for many purposes and as a treatment of diseases too as a medicinal product. Only two studies have been done till now on Camphor addiction and on optic neuritis related to camphorated oil use by Mishra et $\mathrm{al}^{(8)}$. Present study is an important and first study in literature, which is done prospectively among 1233 chronic camphorated oil users and there clinical features.

In present study, we highlighted many interesting findings during the course of study period of 10 years. First, rampant use of camphorated oil has been in all religion, castes, ages and provinces. Second, unrestricted over the counter sale of these oils, even from general merchant stores, apart from medicine shops makes the easy availability to the public. Thirdly, enormous advertisements by film stars personalities have made the common masses to misunderstand these products as useful in various ailments.

In present study, Headache, insomnia, dizziness, psychosis, depression, memory loss, dementia, seizures were the common indication for the use of these camphorated oil. Those patients who have been using it for more than 5 Years, have also experienced multiple withdrawal symptoms like dizziness, headache, nausea, vomiting, diarrhea after stopping the use of camphorated oil, making them addict to these products again over the period.

We found that in total 18039 patients of headache $1 / 4^{\text {th }}$ of patients were using camphorated oil for many different purposes. Most of these camphor addicted patients were of middle aged and older females. In our study there was significant association of camphorated oil use and female 
sex, $99 \%$ patients of camphor addicts were females. Over the period of study we assessed that $25 \%$ patients had re-addiction to the camphor use. Many of patients had psychological withdrawal symptoms on stopping the use of camphor oil leading them to re-addiction over the time.

Camphorated oil has been implicated in neurotoxicity in the past in many studies causing seizures ${ }^{(9)}$, optic neuritis ${ }^{(8)}$. In present study we found $10 \%$ patients in chronic camphor addicted patients had symptoms of visual blurring and of these total 118 patients $18.6 \%$ found to have cerebral atrophy on neuroimaging. There are no studies till now about imaging correlation and camphor addiction in the past. These patients on further evaluation showed low serum vit B12 level also showing association between camphor addiction and its toxicity related to low Vit B12 levels. Serum B12 levels may be effecting the further neurotoxicity of camphor oil in these patients. In our study significant number of patients who had neurotoxicity symptoms also showed associated depression.

This study highlights the unwanted use of camphor oil in general public and misconception about its medicinal effects. This is first study in medical literature which focused on camphor oil addiction and its various neurological symptoms and toxicities. Present study also showed significant association between camphor oil addiction and visual blurring, cerebral atrophy, low serum B12 level and depression.

\section{Conclusion}

Camphor oil is misused over decades by general public for various uses, it's always been publicized by celebrities and media as a wonder medicine and misinformation is given to public leading to rampant use camphor oil. Medical literature has shown toxic effects of camphor use in the past nut no studies have been conducted to prove its addiction and features of toxicity. This study highlights side effects of camphor addiction and need of proper guidelines on camphor sales and its use by general public.

\section{References}

1. Farooq A, Choudhary MI, Atta-urRahman, Tahara S, Başer KH, Demirci F. Detoxification of terpinolene by plant pathogenic fungus Botrytis cinerea. $\mathrm{Z}$ Naturforsch C J Biosci. 2002;57(9-10): 863-866. doi:10.1515/znc-2002-9-1018

2. Marwah P, Marwah A. Camphor poisoning: a rare but preventable cause of status epilepticus. Indian $\mathbf{J}$ Pediatr. 2014;81(9):956. doi:10.1007/s12098-0131306-2

3. Narayan S, Singh N. Camphor poisoningAn unusual cause of seizure. Med J Armed Forces India. 2012;68(3):252-253.

4. Anderson D.L., Topliff A.R. Camphor and mothballs. In: Ford M.D., Delaney K.A., Ling L.J., Erickson T., editors. Clinical Toxicology. WB Saunders; Philadelphia: 2001. pp. 339-342

5. Carracio T.R., McGuigan M.A. Over-thecounter products. In: Dart R.C., editor. Medical Toxicology. 3rd ed. Lippincott Williams \& Wilkins; Philadelphia: 2004. pp. 1051-1062

6. Suresh C. Sikka, Alma R. Bartolome Perfumery, Essential Oils, and Household Chemicals Affecting Reproductive and Sexual Health : Bioenvironmental Issues Affecting Men's Reproductive and Sexual Health, 2018

7. Clifford K. Bridge : HAZARDS OF CAMPHORATED OIL CAN MED ASSOC J OCT. 1, 1995; 153

8. Mishra Vijay. Camphorated Oil Related Optic Neuritis: Review of 21 Cases. JMSCR Volume 2 : Issue 5 ; 1144-1148 : May 2014

9. Patra C, Sarkar S, Dasgupta MK, Das A. Camphor poisoning: An unusual cause of seizure in children. J Pediatr Neurosci. 2015;10(1):78-79. 